\title{
Mechanisms and therapeutic targets of ischemic acute kidney injury
}

\author{
Sang Jun Han*i[, H. Thomas Lee* (i) \\ Department of Anesthesiology, College of Physicians and Surgeons of Columbia University, New York, NY, USA
}

\begin{abstract}
Acute kidney injury (AKI) due to renal ischemia reperfusion (IR) is a major clinical problem without effective therapy and is a significant and frequent cause of morbidity and mortality during the perioperative period. Although the pathophysiology of ischemic AKI is not completely understood, several important mechanisms of renal IR-induced AKI have been studied. Renal ischemia and subsequent reperfusion injury initiates signaling cascades mediating renal cell necrosis, apoptosis, and inflammation, leading to AKI. Better understanding of the molecular and cellular pathophysiological mechanisms underlying ischemic AKI will provide more targeted approach to prevent and treat renal IR injury. In this review, we summarize important mechanisms of ischemic AKI, including renal cell death pathways and the contribution of endothelial cells, epithelial cells, and leukocytes to the inflammatory response during ischemic AKI. Additionally, we provide some updated potential therapeutic targets for the prevention or treatment of ischemic AKI, including Toll-like receptors, adenosine receptors, and peptidylarginine deiminase 4. Finally, we propose mechanisms of ischemic AKI-induced liver, intestine, and kidney dysfunction and systemic inflammation mainly mediated by Paneth cell degranulation as a potential explanation for the high mortality observed with AKI.
\end{abstract}

Keywords: Acute kidney injury, Apoptosis, Inflammation, Ischemia reperfusion injury, Mechanism, Necrosis

\section{Introduction}

Acute kidney injury (AKI) supplanted the older term acute renal failure and is defined as sudden (within hours to days) decline in the glomerular filtration rate, resulting in the retention of nitrogenous wastes, such as urea and creatinine in plasma. In 2007, the Acute Kidney Injury Network (AKIN) classification was introduced as a modified diagnostic criteria for AKI from the Risk, Injury, and Failure; and Loss, and End-stage kidney disease criteria

Received June 1, 2019; Revised July 13, 2019; Accepted July 17, 2019

Edited by Gheun-Ho Kim, Hanyang University, Seoul, Republic of Korea

\section{Correspondence:}

H. Thomas Lee

Director of Transplantation Anesthesiology, Department of Anesthesiology, Anesthesiology Research Laboratories, Columbia University, P\&S Box 46 (PH-5), 630 West 168th Street, New York, NY 10032, USA. E-mail: tl128@columbia.edu

Sang Jun Han

Department of Anesthesiology, Anesthesiology Research Laboratories, Columbia University, P\&S Box 46 (PH-5), 630 West 168 th Street, New York, NY 10032, USA. E-mail: kshlove43@nate.com

*Sang Jun Han and H. Thomas Lee contributed equally to this work.

Copyright (C) 2019 by The Korean Society of Nephrology

@ This is an open-access article distributed under the terms of the Creative Commons Attribution Non-Commercial License (http://creativecommons.org/ licenses/by-nc-nd/4.0/), which permits unrestricted non-commercial use, distribution, and reproduction in any medium, provided the original work is properly cited. 
to increase the sensitivity and specificity of AKI detection $[1,2]$. The AKIN criteria define AKI as "an abrupt (within 48 hours) reduction in kidney function, currently defined as an absolute increase in serum creatinine of either $\geq 0.3$ $\mathrm{mg} / \mathrm{dL}(\geq 26.4 \mathrm{mmol} / \mathrm{L})$, a percentage increase of $\geq 50 \%$ (1.5 fold from baseline), or a reduction in urine output (documented oliguria of $<0.5 \mathrm{~mL} / \mathrm{kg} /$ hour for $>6$ hours)" [2]. Before AKIN criteria were established, $>20$ different definitions for AKI have been used in published studies. AKI remains a critical problem without any effective therapy or preventive methods despite attempts to standardize the definition for early diagnosis and staging, the development of several novel biomarkers, and progress in understanding the pathophysiological mechanisms. The incidence of AKI is approximately $5 \%$ to $20 \%$ and $20 \%$ to $50 \%$ in hospitalized and intensive care unit patients, respectively $[3,4]$. Patients with dialysis-requiring AKI have $>50 \%$ mortality [5]. Epidemiologic studies have demonstrated that AKI frequently develops into chronic kidney disease and is a major risk factor of end-stage renal disease [6]. In the United States, the estimated inpatient cost related to AKI is $>\$ 10$ billion annually [7].

Renal ischemia reperfusion (IR) injury is a leading cause of perioperative AKI [8]. In various clinical settings, such as major vascular, cardiac and hepatic surgeries, shock, sepsis, trauma, and kidney transplantation, renal IR injury occurs because of the interruption of renal blood flow (ischemia), followed by the subsequent reperfusion [8]. A mismatch in local tissue oxygen and nutrient supply and demand together with the accumulation of toxic byproducts from injured renal cells (e.g., pro-inflammatory cytokines and damage associated molecular patterns [DAMPs]) initiates kidney tubular and endothelial cell injury and consecutive renal dysfunction $[9,10]$. Various pathophysiological mechanisms, including renal tubular apoptosis, necrosis, and inflammation, contribute to ischemic AKI. In this review, we summarize cellular and molecular components in the pathophysiology of ischemic AKI and several promising novel therapies currently under investigation.

\section{Mechanism of cell death in ischemic AKI}

The fate of the tubular cells after ischemic AKI depends on the extent of the injury. Mild (sublethal) injury induces loss of cell polarity, such as mislocalization of adhesion molecules/membrane proteins and disruption of cytoskeletal integrity, and cells could recover if the insult is interrupted, whereas more severe (lethal) injury induces irreversible renal tubular cell death by apoptosis or necrosis, resulting in renal dysfunction observed in AKI. In this section, we provide an overview of candidate pathways of cell death after renal IR injury and summarize the emerging evidence for the relative contribution of these pathways to ischemic AKI.

\section{Apoptosis and renal IR injury}

Apoptosis is a programmed cell death characterized by energy-dependent biochemical mechanisms and morphologic changes, including shrinkage of the cell and nucleus, chromatin condensation, and deoxyribonucleic acid (DNA) fragmentation, followed by rapid engulfment of the cellular corpse by macrophages and neighboring viable epithelial cells. Apoptotic cell death occurs via several pathways, including the intrinsic pathway (mitochondrial permeability transition [MPT] pore, Bcl-2 family, cytochrome $c$, caspase-9), extrinsic pathway (death receptor, Fas, FADD, caspase-8), and crosstalk between the intrinsic and extrinsic pathways during ischemic AKI $[11,12]$. In the intrinsic pathway, cellular stress induces cytochrome $c$ release from the mitochondria through $\mathrm{Bax} /$ Bak oligomerization-mediated mitochondrial outer membrane permeabilization, and the released cytochrome $c$ binds with Apaf- 1 to recruit and activate caspase-9, which initiates the final enzymatic cascades of apoptosis by caspase-3. In the extrinsic apoptotic pathway, ligands, such as Fas, bind to death receptors (Fas receptors) and lead to adapter protein (FADD) recruitment and subsequent caspase- 8 activation, which further activates caspase-3. Active caspase- 8 also induces the intrinsic pathway by cleaving Bid to truncated Bid, which translocates to the mitochondria to activate the intrinsic pathway to amplify the apoptotic cascade. Therefore, the mitochondrial integrity is a key mediator linking the intrinsic and extrinsic apoptosis signal pathways, and Bcl-2 family proteins are the key regulators of mitochondrial integrity. The balance between proapoptotic Bcl-2 (multi-BH domain proteins, such as Bax and Bak, and BH3-only proteins, such as Bid and PUMA) and anti-apoptotic Bcl-2 family proteins (Bcl-2 and Bcl${ }_{\mathrm{x}} \mathrm{L}$ ) can determine cellular fate. Anti-apoptotic Bcl-2 pro- 
teins protect cells from apoptotic cell death by preserving mitochondrial integrity, whereas pro-apoptotic proteins induce apoptotic cell death by permeabilizing the mitochondrial membrane. Renal IR injury increases Bax and decreases Bcl-2 by markedly altering the Bax/Bcl-2 ratio in a pro-apoptotic direction in human [13], murine [14] and rat [15] kidneys. Recently, Wei et al [16] reported the critical role of Bax and Bak in tubular cell apoptosis in ischemic AKI by using Bax or Bak knockout mice. They found that the proximal tubule-specific Bax deletion or global Bak knockout protected mice from ischemic AKI.

\section{Necrosis and renal IR injury}

Necrosis is passive non-energy-dependent cell death and is distinguished from apoptosis by cellular swelling and breakdown of plasma membrane integrity that causes release of DAMPs, such as high mobility group box 1 (HMGB1), adenosine triphosphate (ATP), DNA, and ribonucleic acid (RNA). The ischemic insult induces severe and rapid ATP depletion, resulting in mitochondrial injury preferentially with subsequent breakdown of oxidative phosphorylation, further energy depletion, and massive formation of reactive oxidative species (ROS) during reperfusion, which mediates further cellular injury. Necrosis is not dependent on caspase activation but rather on combined results from intracellular calcium accumulation and protease activation. Many studies have shown that ATP depletion induces impairment of calcium ATPase and $\mathrm{Na}^{+}-\mathrm{K}^{+}$-ATPase, resulting in intracellular calcium accumulation. Elevated cytosolic calcium levels cause further mitochondrial injury, cytoskeletal alteration, and protease activation, such as calpain and phospholipases, which induce plasma membrane permeability and cytoskeleton protein degradation.

\section{Necroptosis and renal IR injury}

Until recently, necrosis has been considered as an accidental and non-regulated cell death rather than the results of defined signaling events. However, recent studies changed this dogma, and necrosis can clearly occur in a regulated manner by MPT-mediated regulated necrosis, necroptosis, ferroptosis, pyroptosis, and poly (ADP-ribose)-polymerase 1 (PARP1)-mediated regulated necrosis [17]. Among regulated necrosis pathways, necroptosis is the most studied pathway in kidney diseases, including renal IR, cisplatin-, contrast- and folic acidinduced AKI [18]. The necroptosis pathway is mainly mediated by cytoplasmic receptor-interacting protein kinase 3 (RIPK3), RIPK1, and mixed lineage kinase domain-like protein (MLKL). Tumor necrosis factor- $\alpha$ (TNF- $\alpha$ ) is the best studied ligand that initiates the necroptosis pathway; however, necroptosis is also initiated by other ligands, such as Fas ligand, Toll-like receptors (TLR3 and TLR4), and interferons [18]. Several studies have suggested the role of necroptosis in renal IR injury using knockout mice or pharmacological inhibitors for these necroptosis major mediators (RIPK1, RIPK3, and MLKL). von Mässenhausen et al [19] reported that RIPK3 or MLKL knockout mice have been protected from renal ischemic injury, and Linkermann et al [20] found that RIPK3 deficiency in mouse improved the survival rate after severe ischemia (43-minute ischemia), and they also determined that pretreatment of Nec-1, a kinase activity inhibitor of RIPK1, prevents renal IR injury in mice. Unlike necroptosis, the contribution of other regulated necrosis is incompletely understood.

\section{Inflammation and ischemia AKI}

\section{Contribution of endothelial and tubular cells to inflammation after renal IR injury}

Increasing evidence indicates that both innate and adaptive inflammatory responses play major roles in the pathogenesis of ischemic AKI, and inflammatory cascades are initiated by a combination of endothelial cell injury, and activation and interaction with leukocytes via adhesion molecules [21]. During the extension phase, renal IR injury causes disruptions of the perivascular matrix, such as the glycocalyx and endothelial monolayer, resulting in increased endothelial barrier permeability. Breakdown of the endothelial barrier might be caused by activation of matrix metalloproteinase (MMP)-2 or MMP9 [22]. Treatment with minocycline, a broad-spectrum inhibitor of MMPs, or MMP-2-specific gene deletion ameliorates the increase in microvascular permeability and kidney injury in rat [23] or mouse [24] models of ischemic AKI. In addition to endothelial cell injury, IR injury causes endothelial cell activation through upregulation of adhesion molecules, such as E-selectin, P- 
selectin, vascular cell adhesion protein-1, and intercellular adhesion molecule-1 (ICAM-1). Activated leukocytes infiltrate into the interstitial compartment by binding to endothelial cells through these adhesion molecules. Many studies reported that blocking or genetic deletion of these adhesion molecules protect against kidney injury in animal models of renal ischemia [25-27]. Activated leukocytes can also lead to further endothelial cell injury and dysregulation of the endothelial barrier permeability [28]. Renal tubular epithelial cells can also contribute to the inflammatory response in kidney IR injury by producing pro-inflammatory cytokines (e.g., TNF- $\alpha$, interleukin [IL]-6, IL-1 $\beta$, transforming growth factor [TGF]- $\beta$ ) and chemokines (e.g., monocyte chemoattractant protein-1 [MCP-1], IL-8, regulated on activation, normal $\mathrm{T}$ cell expressed and secreted [RANTES]) [29]. In addition to generating pro-inflammatory cytokines and chemokines, tubular cells also express TLRs, complement and complement receptors, and costimulatory molecules, such as B7-1 and B7-2 that interact with CD28 on T lymphocytes and facilitate cytokine production [30].

\section{Neutrophils and inflammation after renal IR injury}

Neutrophils are the earliest leukocytes to accumulate in the kidney after ischemic injury in animal models and human AKI and are the major contributors to additional renal injury after reperfusion through release of ROS, proteinases, elastases, myeloperoxidase, and cationic peptides [31]. Neutrophils secrete pro-inflammatory cytokines and chemokines to create a positive feedback loop of neutrophil recruitment and activation, as well as other inflammatory leukocytes, including natural killer cells, monocytes, and macrophages, mediating kidney injury via synergistic interaction [32-34]. Resident dendritic cells also initiate a potent chemotactic gradient for neutrophil recruitment by releasing TNF- $\alpha$, IL-6, MCP1 , RANTES, macrophage inflammatory protein-2 (MIP2) and keratinocyte chemoattractant (KC) (the mouse analog of human IL-8), which plays a critical role in neutrophil recruitment particularly in the kidney [31,34]. Stimulated neutrophils are the most intense physiological producers of superoxide anions through the activation of the NADPH oxidase 2 upon adhesion or by proinflammatory cytokines. The superoxide subsequently dismutates to hydrogen peroxide $\left(\mathrm{H}_{2} \mathrm{O}_{2}\right)$ by superoxide dismutase. In addition, superoxide anions can be converted to other ROS, such as hypochlorous acid $(\mathrm{HOCl})$ and hydroxyl radical $\left(\mathrm{OH}^{-}\right)$by myeloperoxidase (MPO) $[9,10,31]$. Studies on therapeutic targeting neutrophils have been conflicting since some reported that inhibiting neutrophil infiltration ameliorates kidney injury in animal model of ischemic AKI [25,35], whereas other studies failed to observe the protective effect of neutrophil blockade or depletion on ischemic AKI [36,37]. Despite discrepancies in conclusions of those studies, blocking several adhesion molecules involved in neutrophil and other leukocyte infiltration, such as ICAM-1 [25], selectins $[27,38]$, and CD11a/11b [39], has shown a protective effect in rodent ischemic AKI models, indicating that neutrophils are not the only leukocytes that contribute to renal IR injury, and other leukocytes together with neutrophils contribute to ischemic kidney injury via synergistic interaction.

\section{Macrophage and inflammation after renal IR injury}

Macrophages are also critical participants in the innate immune response during the initial period of renal IR injury but are also promoters of tubular repair and longterm kidney fibrosis after ischemic injury. The distinct function of macrophages is due to its heterogeneity (M1 and M2 macrophage). In mouse ischemic kidney, macrophage infiltration starts increasing significantly at 1 hour, peaking at 24 hours, and persisting over 7 days following reperfusion [40]. C-C motif chemokine receptor 2 and fractalkine receptor (CX3CR1) are key mediators for infiltration of inflamed/inflammatory monocytes into injured kidneys following renal IR injury [40,41]. Infiltrated and activated macrophages (M1) after renal IR injury induce kidney tissue injury by producing abundant ROS, nitrogen intermediates, and pro-inflammatory cytokines (including IL-1 $\beta$ and TNF- $\alpha$ ) that can stimulate the activity of other leukocytes and drive a polarized Th1 immune response [42]. In mice, Day et al [43] have shown that depletion of kidney and spleen macrophages using liposomal clodronate before renal IR prevented AKI, whereas adoptive transfer of macrophages (RAW 264.7 cells) reconstituted ischemic AKI. However macrophage depletion during the recovery phase of renal IR injury diminished tubular cell proliferation and delayed tubular repair [44], indicating that macrophages (M2) are also 
critical mediators for kidney repair after renal IR injury. If the tubular cell proliferation and repair process is well established, pro-repair M2 macrophages predominate in the tissue [44] and can provoke a Th2 cell activation [42].

Dendritic cells and inflammation after renal IR injury

Dendritic cells expressing CD11c and MHC class II are abundant in the interstitium in normal mouse kidneys [45] and have an important role in linking between innate and adaptive immunity [42]. Dendritic cells are key initiators and potentiators of the innate immune system by releasing pro-inflammatory cytokines/chemokines (TNF, IL-6, MCP-1, and RANTES) [46], interacting with natural killer $\mathrm{T}$ (NKT) cells via presenting glycolipids via the CD1d molecule to activate invariant NKT (iNKT) cells [47]. Furthermore, direct cellular contact between dendritic and iNKT cells by binding CD40/CD40L induces a strong feed-forward signal of IL-12 production, which triggers Stat4 phosphorylation and consecutive interferon (IFN)- $\gamma$ secretion in iNKT cells [47]. In addition, activation of CD1d-restricted NKT cells contributed to renal IR injury by promoting IFN- $\gamma$ producing infiltration [48].

\section{Potential therapeutic targets}

The pathophysiological mechanism of ischemic AKI on a cellular and molecular level, including cell death, cell injury, inflammation, and systemic immune dysregulation have been previously discussed. The pharmacological targeting of these injury mediators and corresponding signal pathway could provide new therapeutic opportunities. Endogenous DAMPs released by dying cells activate cellular receptors leading to downstream inflammation and cell death after renal IR injury. Here, we focus on novel signaling mediators, including DAMPs and their putative receptors in the pathogenesis of ischemic AKI. In addition, we will provide pathophysiological mechanisms involved in remote organ injury during AKI because recent clinical data suggest that AKI also contributes to the development and exacerbation of multiorgan dysfunction, including the liver and gastrointestinal (GI) tract, leading to severe complications associated with high mortality.
Toll-like receptors and renal IR injury

TLRs are transmembrane pattern recognition receptors expressed in leukocyte and other cell types, including renal tubular epithelial cells. TLRs have a central role in activating the innate immune responses upon recognition of exogenous microbial ligands (pathogenassociated molecular patterns [PAMPs]) [49]. Humans and mice have 10 (TLR1-10) and 12 (TLR1-9, 11-13), respectively [50,51]. Different types of TLRs recognize specific PAMPs. TLRs on the cell surface (TLR1/2/4/5/6) or in intracellular endosomes (TLR3/7/8/9) recognize potential pathogens by ligating PAMPs, such as lipopolysaccharide (TLR4), flagellin (TLR5), bacterial cell wall components (TLR1/2/6), and viral/bacterial nucleic acids (TLR3/7/8/9) [52]. In a setting of AKI, TLRs also detect endogenous ligand DAMPs, including histones, highmobility group box 1, heat shock proteins, hyaluronan, fibronectin, and mitochondrial DNA [52]. Mainly, TLR2 and TLR4 have been implicated in mediating renal IR injury and are constitutively expressed in kidney tubular cells, including the proximal and distal tubules, thin limb of the loop of Henle, and collecting ducts [53], and both expressions of TLR2 and TLR4 are increased in these tubules after renal IR injury [53]. Numerous studies using TLR2 and/or TLR4 knockout mice demonstrated that TLR2 and TLR4 play a crucial role in kidney IR injury. Shigeoka et al [54] found that both TLR2- or myeloid differentiation factor 88 (MyD88, the central TLR signaling adaptor)-knockout mice were protected from renal IR injury, and TLR2 deficiency has a more protective effect on renal IR injury, suggesting that TLR2 contributes to renal IR injury through MyD88-dependent and MyD88independent pathways. Wu et al [55] have shown that sublethal renal IR injury induced upregulation of endogenous ligands for TLR2 and TLR4, such as HMGB1, biglycan, and hyaluronan, and they found that TLR4 signaling in intrinsic kidney cells rather than bone marrowderived cells plays the dominant role in mediating renal IR injury by generating chimeric mice using bone marrow transplantation. In a clinical setting, a phase II clinical trial was conducted to evaluate the safety, tolerability, and efficacy of OPN-305, a humanized monoclonal antibody that blocks TLR2, in renal transplant patients at high risk for delayed graft function (ClinicalTrials.gov Identifier:NCT01794663). TLR9 is also suggested as a po- 
tential mediator for ischemic AKI because several studies reported that TLR9 activation plays a critical role in hepatic [56,57], cardiac [58], and cerebral [59] IR injury, and renal IR injury induces plasma mitochondrial DNA release, which is an endogenous ligand for TLR9 [60]. However, two previous studies reported that global TLR9 deletion had no effect on kidney IR injury $[61,62]$. We also confirmed that mice globally deficient in TLR9 were not protected against ischemic AKI [63], whereas renal proximal tubular TLR9 deletion protects ischemic AKI by ameliorating necrosis, apoptosis, and inflammation after IR by suppressing nuclear factor (NF) $\mathrm{KB}$-mediated proinflammatory pathway and caspase-3/8 apoptosis pathway (Fig. 1) [63]. These differences suggest divergent effects of TLR9 activation, depending on the cell and tissue types. Indeed, intestinal TLR9 deletion exacerbates renal IR injury [60].

\section{Adenosine receptors and renal IR injury}

Adenosine is an endogenous compound produced by all mammalian cells and is present in the intra- or extracellular space. Extracellular adenosine binds to cell surface receptors to mediate various physiological and pathological activities [64]. Recent evidence suggests that extracellular adenosine controls cellular adaptation to hypoxia $[64,65]$. Extracellular adenosine production is mainly derived from the phosphohydrolysis of adenosine monophosphate (AMP) and ATP via serial enzymatic actions of ecto-nucleoside-triphosphate-diphosphohydrolasel (E-NTPDase1 or CD39), which converts ATP to AMP, which is converted to adenosine by ecto-5' nucleotidase (CD73) [66]. Numerous studies suggest that adenosine is protective during renal IR injury [65]. To date, four adenosine receptor subtypes $\left(A_{1} A R, A_{2 A} A R\right.$, $A_{2 B} A R$, and $A_{3} A R$ ) have been identified and classified based on their differential coupling to adenylyl cyclase to regulate cyclic AMP levels. All four adenosine receptors are implicated in ischemic AKI. Using pharmacological and deletion of $A_{1} A R$ in mice, the role of $A_{1} A R s$ in ischemic AKI induced by renal IR injury was investigated. $A_{1} A R$ knockout mice or selective $A_{1} A R$ antagonist-treated mice exhibited significantly higher plasma creatinine levels and worsened renal histology with increased markers of renal inflammation (neutrophil infiltration and proinflammatory cytokine mRNA expressions). Conversely, selective $A_{1} A R$ agonist treatment protect against renal IR injury [67]. In another study, $A_{1} A R$ activation protects against both acute and delayed renal IR injury via distinct signaling pathways. Acute $\mathrm{A}_{1} \mathrm{AR}$-mediated protection is mediated via phosphorylation of extracellularsignal-regulated kinase (ERK) mitogen-activated protein kinase (MAPK), Akt, and heat shock protein 27 (HSP27), whereas delayed $\mathrm{A}_{1} \mathrm{AR}$-mediated protection is mainly by

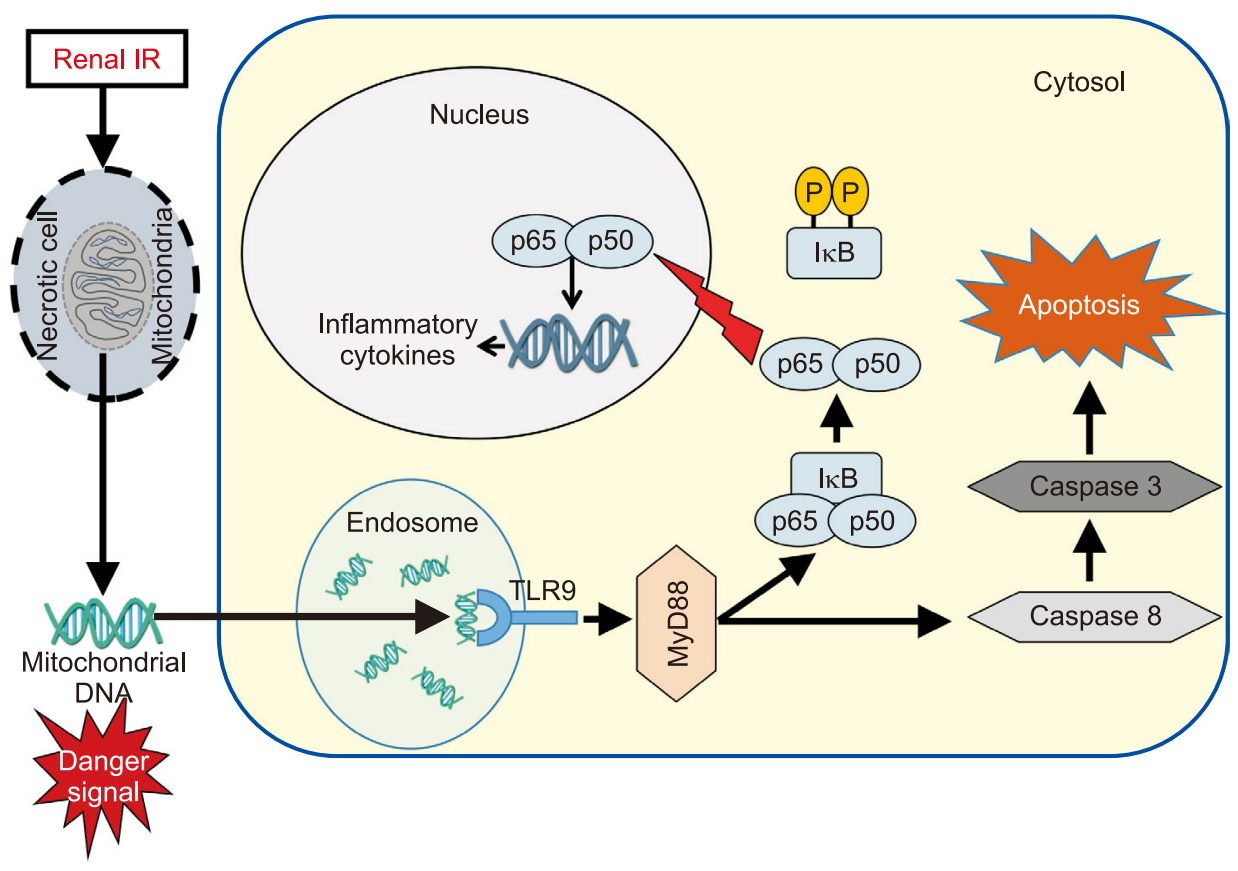

Figure 1. Schematic of proposed mechanisms for renal proximal tubular Tolllike receptor 9 (TLR9)-mediated exacerbation of ischemic acute kidney injury (AKI). After renal ischemia reperfusion (IR) injury, endogenous TLR9 is activated by TLR9 ligand (presumably mitochondrial deoxyribonucleic acid [DNA] products), and TLR9 activation leads to NFKBmediated induction of pro-inflammatory chemokines and cytokines and caspase 3/8-mediated renal tubular apoptosis. $I_{\kappa} B$, inhibitor of $\kappa B$; MyD88, myeloid differentiation factor 88 ; $N F_{\kappa} B$, nuclear factor kappa-light-chain-enhancer of activated $B$ cells. 
a dramatic induction of HSP27 [68]. Moreover, intrarenal injection of lentivirus encoding human- $A_{1} A R$ in both wild-type or $A_{1} A R$-knockout mice have been confirmed to show dramatic improvements in renal function with reduced inflammatory infiltrates and increased HSP27 levels compared with controls [69].

Other studies suggest that $\mathrm{A}_{2 \mathrm{~A}} \mathrm{AR}$ is also implicated in kidney tissue protection from renal IR injury. Using chimeric mice, with transfer of bone marrow from $\mathrm{A}_{2 \mathrm{~A}} \mathrm{AR}$ knockout to wild-type mice and vice versa, Day et al [70] demonstrated that $\mathrm{A}_{2 \mathrm{~A}} \mathrm{AR}$ present on bone marrowderived cells but not on kidney tissues mediates renal protection against renal IR injury, and they showed that $\mathrm{A}_{2} \mathrm{AR}$ activation on bone marrow-derived cells reduces induction of pro-inflammatory IL-6, IL-1 $\beta$, and IL-1ra and TGF- $\beta$ mRNAs in the kidneys after renal IR injury. In a further study by the same group, $\mathrm{A}_{2 \mathrm{~A}} \mathrm{AR}$ signaling on $\mathrm{CD}^{+}$cells Treg cells mediated renal protection against renal IR injury using chimeric mice, with transfer of bone marrow from $A_{2 A} A R$ knockout to mice lacking $T$ and $B$ cells (Rag- ${ }^{-/-}$) and vice versa [71]. $A_{2 B} A R$ is also shown to be beneficial in renal IR injury. Grenz et al [72] examined the role of different adenosine receptors in ischemic precondition (IP)-mediated protection against renal IR injury. Of the four ARs, only $A_{2 B} A R$ gene deletion or $A_{2 B} A R$ antagonist PSB1115 treatment abolished IP-mediated protection after renal ischemia, and this protection was associated with corresponding changes in tissue inflammation and NO production. They also found that unlike $A_{2 A} A R, A_{2 B} A R s$ on renal parenchymal (endothelial and/or tubular epithelia) rather than on leukocytes conferred renal protection against IR injury because $A_{2 B} A R$ knockout mice with wild-type bone marrow show IP-mediated or $\mathrm{A}_{2 \mathrm{~B}} \mathrm{AR}$ activator (BAY 60-6583)-mediated renal protection against renal IR injury similar to that of wild-type mice [72]. $\mathrm{A}_{3} \mathrm{AR}$ gene deletion or pharmacological inhibition of

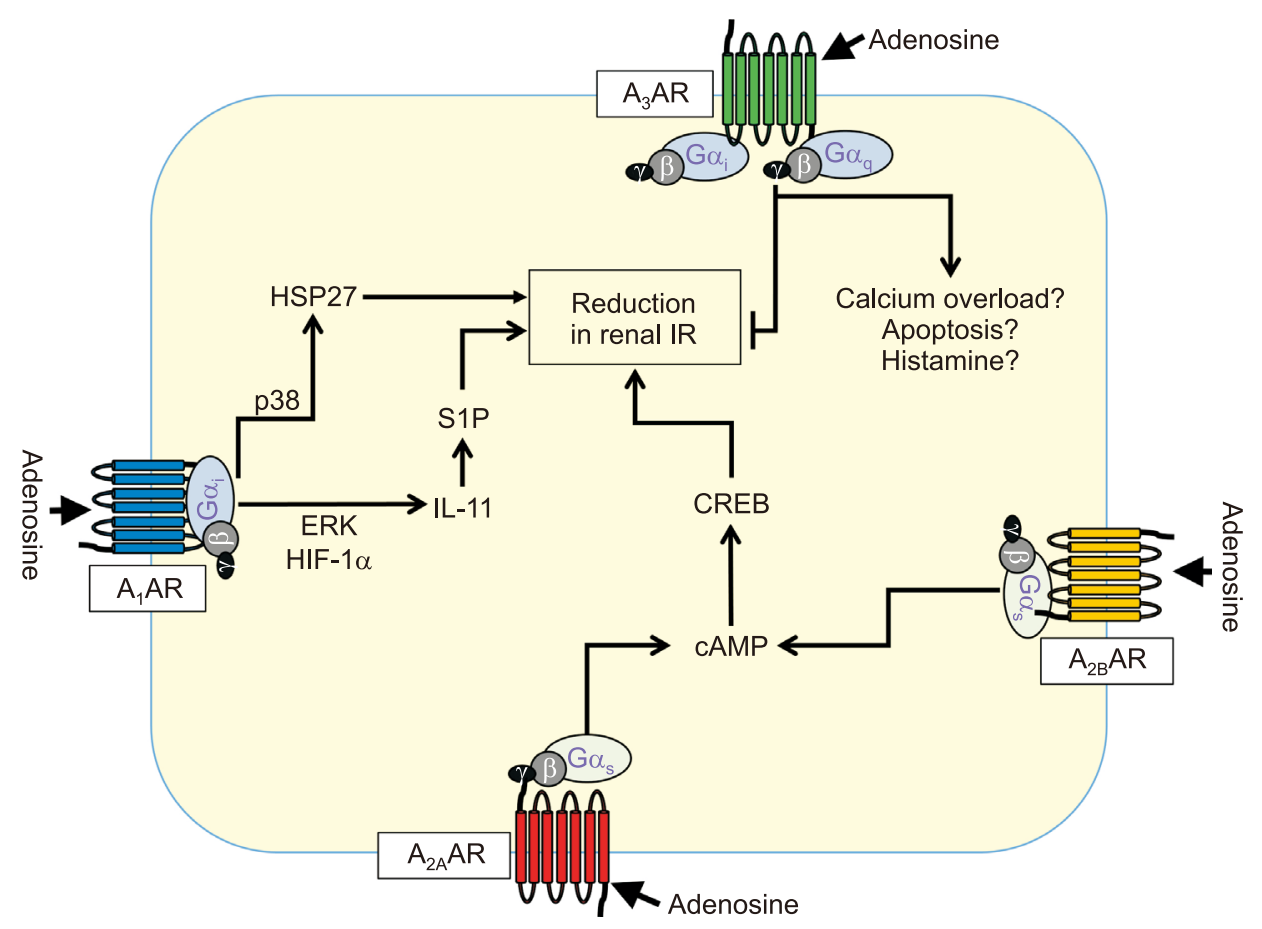

Figure 2. Schematic of proposed mechanisms for $A_{1} A R$-mediated protection against renal ischemia reperfusion (IR) injury. $A_{1} A R$ activation by adenosine binding to $A_{1} A R$ induces synthesis of a cytoprotective cytokine interleukin (IL)-11 via extracellular-signal-regulated kinase (ERK) and hypoxia inducible factor 1-alpha (HIF-1 $\alpha$ ) activation, and IL-11 subsequently induces sphingosine kinase-1 synthesis, which phosphorylates sphingosine to another cytoprotective molecule sphingosine-1-phosphate (S1P). $\mathrm{A}_{1} \mathrm{AR}$ also phosphorylates and induces cytoprotective heat shock protein 27 (HSP27) synthesis via p38 MAPK activation, resulting in decreased renal tubular apoptosis and inflammation. $A_{2 A} A R$ and $A_{2 B} A R$ increase cyclic adenosine monophosphate (cAMP) levels by stimulating adenylate cyclase and activating protein kinase $A$, which causes translocation of CAMP response-element binding protein into nuclear to produce cytoprotection. $A_{3} A R$ activation seems to stimulate apoptosis and calcium overload, leading to enhanced renal injury after ischemia and reperfusion.

$\mathrm{AR}$, adenosine receptor. 
$\mathrm{A}_{3} \mathrm{AR}$ in mice has renal protective effect against ischemiaand myoglobin-induced renal injury [73]. Moreover, selective $A_{3} A R$ activation has been shown to worsen renal IR injury, whereas $\mathrm{A}_{3} \mathrm{AR}$ inhibition protected against renal IR injury in rats [74]. In contrast, we and others found that $\mathrm{A}_{3} \mathrm{AR}$-activation protects tissue injury in septic AKI [75], hepatic IR injury [76], or myocardial infarction [77], suggesting that $\mathrm{A}_{3} \mathrm{AR}$ differentially modulates tissue injury, depending on tissues or the type of renal injury. We summarize the proposed mechanisms for AR-mediated regulation of renal IR injury in Fig. 2.

\section{Peptidylarginine deiminase 4 and ischemic AKI-induced inflammation}

ATP is released by wide range of stimuli, such as hypoxia, mechanical stress, cell membrane damage, inflammation [64]. Recently, extracellular ATP has been recognized as a danger signal and implicated in ischemia-driven inflammatory response and tissue injuries [64]. Extracellular ATP promotes inflammatory responses by binding to purinergic receptors, such as $\mathrm{P}_{2} \mathrm{X}_{7}$ receptor. Indeed, several studies reported that pharmacological and/or genetic blockade of $\mathrm{P}_{2} \mathrm{X}_{7}$ receptors protects against isch- emic AKI mainly by inducing Treg cell expansion $[78,79]$. In our previous studies, we showed that $\mathrm{P}_{2} \mathrm{X}_{7} \mathrm{R}$ activation induces renal tubular peptidyl arginine deiminase 4 (PAD4) in ischemic AKI. Renal IR injury induces protein and mRNA, as well as activity of renal tubular PAD4, and pharmacological inhibition or gene deletion of PAD4 protects kidney from renal IR injury by reducing inflammatory response and apoptosis [80,81]. In additional studies, we demonstrated that ATP induces renal tubular PAD4 via protein kinase $\mathrm{C}$ signaling, and PAD4 is the critical mediator of $\mathrm{P}_{2} \mathrm{X}_{7}$-mediated kidney inflammation and injury after renal IR injury because the $\mathrm{P}_{2} \mathrm{X}_{7}$ receptor failed to exacerbate ischemic AKI in PAD4 knockout mice [82]. Furthermore, we found that PAD4 preferentially citrullinates inhibitor of $\kappa \mathrm{B}$ (IКB) kinase- $\gamma(\mathrm{IKK}-\gamma$, also known as $\mathrm{NF}_{\kappa} \mathrm{B}$ essential modulator or NEMO) over other IKK subunits, IKK- $\alpha$ or IKK- $\beta$. Inhibition of NEMO by NEMO-binding peptide attenuated PAD4-mediated exacerbation of ischemic AKI, apoptosis, and inflammation, suggesting that NEMO citrullination is a central mediator of both PAD4 and $\mathrm{P}_{2} \mathrm{X}_{7}$-mediated ischemic AKI [83]. We summarize our previous and current findings and proposed a detailed mechanism of PAD4-mediated renal tubular inflammation and exacerbation of ischemic

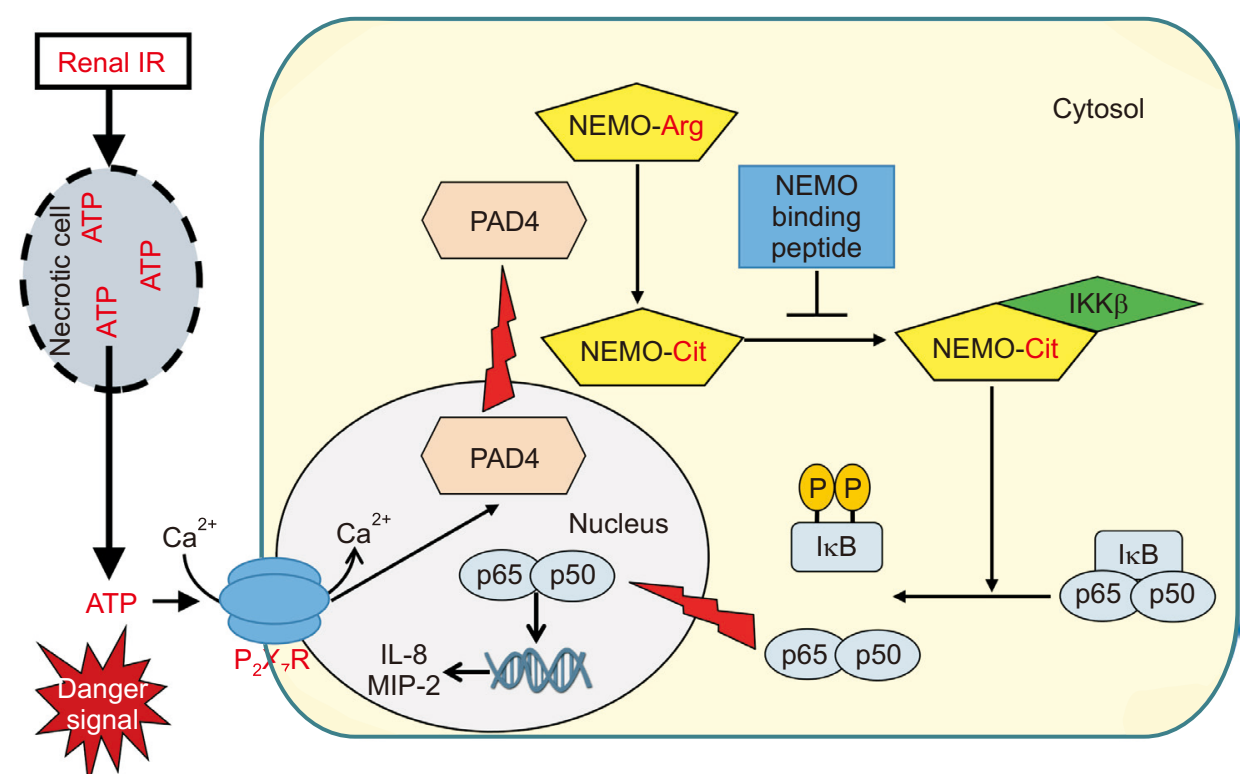

Figure 3. Schematic of proposed mechanisms for peptidylarginine deiminase 4 (PAD4)-mediated inflammation via nuclear factor KB essential modulator (NEMO) activation. Released intracellular adenosine triphosphate (ATP) from necrotic renal tubular cells by renal ischemia reperfusion (IR) injury induces PAD4 activation and cytosolic translocation in neighboring renal proximal tubular cells via $\mathrm{P}_{2} \mathrm{X} 7$ receptor activation and protein kinase $\mathrm{C}$ (PKC) signaling. Activated and translocated PAD4 into the cytoplasm preferentially citrullinates NEMO and induces cytokine/chemokine synthesis and neutrophil infiltration in the kidney via NFKB signaling pathway.

$\mathrm{IKK}$, inhibitor of $\kappa B\left(\mathrm{I}_{\kappa} \mathrm{B}\right)$ kinase; IL, interleukin; $\mathrm{P}_{2} \mathrm{X}_{7}$ receptor, $\mathrm{P}_{2} \mathrm{X}$ purinoceptor 7 . 
AKI in Fig. 3.

\section{Multiorgan dysfunction (gut-liver-kidney interaction) after ischemic $A K I$}

Recent clinical data suggests that AKI also contributes to the development and exacerbation of multiorgan dysfunction, including the liver, heart, lung, brain, and GI tract, leading to severe complications associated with high mortality [84]. Therefore, understanding the specific pathophysiological mechanisms involved in remote organ injury during AKI is critical for therapeutic interventions to decrease mortality after AKI. Many factors, including leukocyte activation and trafficking, cytokines/ chemokine changes, oxidative stress, and uremic milieu, mediate AKI-induced remote organ dysfunction. Among them, activation of systemic inflammation is the primary pathophysiological mechanism mediating organ crosstalk during AKI.

The liver and small intestines are interconnected by the portal circulation, and the crosstalk between the small intestine and liver is mainly attributable to multiorgan dysfunction after ischemic AKI. The intestines provide important immunologic barrier to prevent large amount of TLR ligands, pro-inflammatory cytokines, and bacterial pathogens from entering the systemic circulation via the portal circulation [85]. In the small intestine, Paneth cells residing at the bottom of the intestinal crypts are the key effectors of innate mucosal defense by releasing antimicrobial peptides, such as lysozyme and $\alpha$-defensins, and they also release pro-inflammatory cytokines, including TNF- $\alpha$ and IL-17A. In a previous study, Paneth cells play a critical role in organ crosstalk among the kidneys, intestines, and liver during ischemic AKI. AKI induced by renal IR injury or bilateral nephrectomy increased IL17A production by Paneth cells, and IL-17A levels in systemic circulation and portal vein were elevated after AKI [86]. IL-17A generated in the intestines is delivered into the liver by macrophages and induces TNF- $\alpha$ and IL- 6 induction in liver, subsequently causing liver injury characterized by inflammation, necrosis, and apoptosis [86]. Moreover, we determined that hepatic and intestinal IR injury also increased IL-17A production by Paneth cells, and Paneth cell depletion or IL-17A neutralization by antibody treatment reduced hepatic, intestinal, and renal injury $[87,88]$, suggesting that IL-17A production by small intestinal Paneth cells may be a major player in multiple organ failure induced by IR injury (Fig. 4). Emerging evidence also suggests the implication of gut microbiome in AKI. Germ-free mice have been initially suggested to be

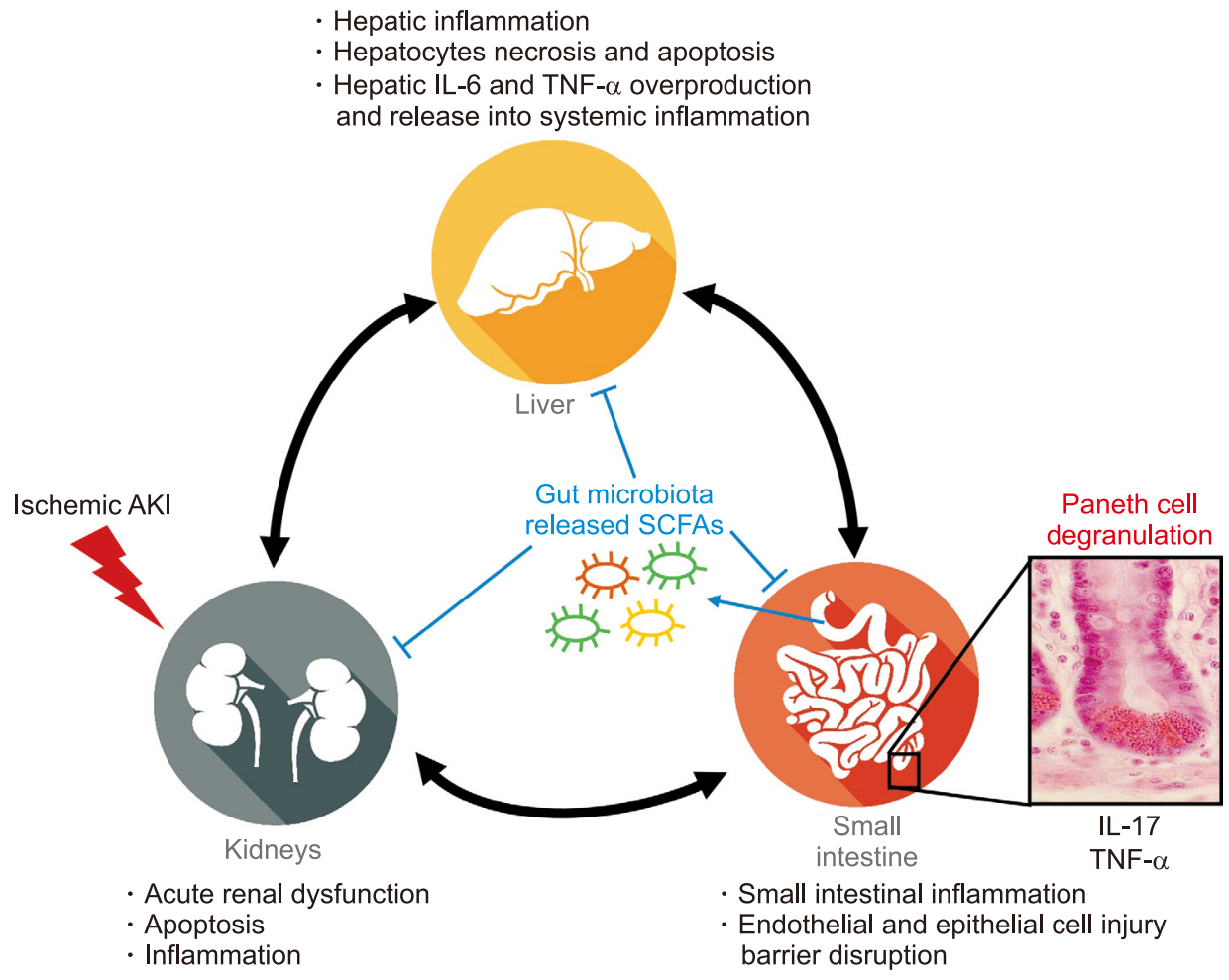

Figure 4. Schematic of proposed mechanisms of ischemic acute kidney injury (AKI)-induced liver, intestine, and kidney dysfunction and systemic inflammation. Acute renal ischemic injury causes small intestinal inflammation, intestinal barrier disruption via endothelial and epithelial cell injury, and release of proinflammatory cytokines, such as interleukin (IL)-17A and tumor necrosis factor- $\alpha$ (TNF- $\alpha$ ), from Paneth cells. Portal delivery of IL-17A by macrophage leads to hepatic injury, including necrosis, apoptosis, and increased generation and systemic release of TNF- $\alpha$ and IL-6, propagating multiorgan injury and systemic inflammation. 
Table 1. Summary of therapeutic targets for ischemic AKI

\begin{tabular}{|c|c|c|c|}
\hline \multicolumn{2}{|c|}{ Target } & \multirow{2}{*}{$\begin{array}{c}\text { Key findings } \\
\text { - TI R2-or MvD88 (the central TI R sionalino adantor) -knockout mice were nrotected from renal IR iniury }\end{array}$} & \multirow{2}{*}{$\frac{\text { Reference }}{[54]}$} \\
\hline TLRs & TLR2 & & \\
\hline & TLR4 & - TLR4 signaling in intrinsic kidney cells plays a dominant role in mediating renal IR injury. & [55] \\
\hline & TLR9 & $\begin{array}{l}\text { - Renal proximal tubular TLR9 gene deletion protects ischemic AKI by ameliorating necrosis, apoptosis, } \\
\text { and inflammation. }\end{array}$ & [63] \\
\hline \multirow[t]{7}{*}{$\begin{array}{l}\text { Adenosine } \\
\text { receptors }\end{array}$} & $A_{1} A R$ & $\begin{array}{l}\text { - } A_{1} A R \text { gene deletion or } A_{1} A R \text { antagonist treatment exacerbated renal IR injury, whereas } A_{1} A R \text { agonist } \\
\text { treatment protected it. }\end{array}$ & [67] \\
\hline & & $\begin{array}{l}\text { - Intrarenal injection of lentivirus encoding human- } \mathrm{A}_{1} \text { AR improved renal function with reduced } \\
\text { inflammatory infiltrates and increased HSP27 levels. }\end{array}$ & [69] \\
\hline & $A_{2 A} A R$ & $\begin{array}{l}\text { - } A_{2 A} A R \text { present on bone marrow-derived cells but not on kidney tissues mediates renal protection } \\
\text { against renal IR injury. }\end{array}$ & [70] \\
\hline & & - $\mathrm{A}_{2 \mathrm{~A}} \mathrm{AR}$ signaling on $\mathrm{CD} 4^{+}$cells Treg cells mediated renal protection against renal IR injury. & [71] \\
\hline & $\mathrm{A}_{2 \mathrm{~B}} \mathrm{AR}$ & $\begin{array}{l}\text { - } \mathrm{A}_{2 \mathrm{~B}} \mathrm{ARs} \text { on renal parenchymal (endothelial and/or tubular epithelia) rather than on leukocytes } \\
\text { conferred renal protection against IR injury. }\end{array}$ & [72] \\
\hline & $\mathrm{A}_{3} \mathrm{AR}$ & $\begin{array}{l}\text { - } \mathrm{A}_{3} \mathrm{AR} \text { gene deletion or pharmacological inhibition in mice have a renal protective effect against } \\
\text { ischemia- and myoglobinuria-induced renal injury. }\end{array}$ & [73] \\
\hline & & - Selective $A_{3} A R$ activation worsened renal IR injury in rat. & {$[74]$} \\
\hline \multirow[t]{3}{*}{ PAD4 } & & $\begin{array}{l}\text { - Pharmacological and/or genetic blockade of } \mathrm{P}_{2} \mathrm{X}_{7} \text { receptors protects against ischemic AKI mainly by } \\
\text { inducing Treg cell expansion. }\end{array}$ & {$[78,79]$} \\
\hline & & - PAD4 is the critical mediator of $\mathrm{P}_{2} \mathrm{X}_{7}$-mediated kidney inflammation and injury after renal IR injury. & [82] \\
\hline & & - NEMO citrullination is a central mediator of both PAD4- and $\mathrm{P}_{2} \mathrm{X}_{7}$-mediated ischemic AKI. & [83] \\
\hline $\begin{array}{l}\text { Remote organ } \\
\text { dysfunction }\end{array}$ & & $\begin{array}{l}\text { - IL-17A production by small intestinal Paneth cells contributes to multiple organ failure induced by IR } \\
\text { injury. }\end{array}$ & [86] \\
\hline
\end{tabular}

AKI, acute kidney injury; HSP27, heat shock protein 27; IL, interleukin; IR, ischemia reperfusion; MyD88, myeloid differentiation factor 88; NEMO, nuclear factor $\kappa B$ essential modulator; PAD4, peptidylarginine deiminase 4; $\mathrm{P}_{2} \mathrm{X}_{7}, \mathrm{P}_{2} \mathrm{X}$ purinoceptor 7 ; TLRs, Toll-like receptors.

more susceptible to renal IR injury with more $\mathrm{CD} 8^{+} \mathrm{NKT}$ cells, and conventionalizing germ-free mice with normal bacteria rescued the harmful effect of germ-free mice of IR injury [89]. Intestinal microbiota produces short-chain fatty acids (SCFAs), such as acetate (C2), propionate (C3), and butyrate (C4). SCFAs have anti-inflammatory effects. Andrade-Oliveira et al [90] determined that three main SCFAs (acetate, propionate, and butyrate) protect against renal IR injury with lower inflammation (decreasing dendritic cells maturation and $\mathrm{CD} 4^{+}$and $\mathrm{CD}^{+} \mathrm{T}$ cell proliferation), oxidative stress, and apoptosis compared with control mice. In contrast to these findings, Emal et al [91] demonstrated that the depletion of gut microbiota with broad-spectrum antibiotics profoundly protects against renal IR injury by reducing maturation status of $\mathrm{F} 4 / 80^{+}$ resident macrophages and bone-marrow derived monocytes in the kidney. These discrepancies in renal IR injury between two main studies suggest the need for more detailed mechanical studies. \\ 436 www.krcp-ksn.org}

\section{Summary}

In this review, we summarized some of the important mechanisms of ischemic AKI mainly focused on cell death, including apoptosis, necrosis and necroptosis, and inflammation mediated by endothelial cells, tubular epithelial cells, and leukocytes, such as neutrophils, macrophages, and dendritic cells. In addition, we provided updated potential therapeutic targets, such as TLRs (TLR2/4/9), ARs, and PAD4 for the prevention or treatment of ischemic AKI. Moreover, we proposed mechanisms of ischemic AKI-induced liver, intestine, and kidney dysfunction and systemic inflammation mainly mediated by Paneth cell degranulation (Table 1) $[54,55,63,67,69-74,78,79,82,83,86]$. Although progress for this disease treatment and prevention is being made on multiple fronts, many hurdles have to be overcome because the mortality and morbidity of this disease only slightly improved after 4 decades. We hope this review helps the researcher and clinician to have a better understanding of the molecular and cellular pathophysiologi- 
cal mechanisms underlying ischemic AKI and to provide more targeted approach to prevent and treat renal IR injury.

\section{Conflicts of interest}

All authors have no conflicts of interest to declare.

\section{Acknowledgments}

This work was supported by the Department of Anesthesiology, College of Physicians and Surgeons of Columbia University, New York, NY, and in part by DK-109544 and DK-115694 (to HTL).

\section{Authors' contributions}

Sang Jun Han and H. Thomas Lee drafted manuscript. Sang Jun Han and H. Thomas Lee edited and revised manuscript. Sang Jun Han and H. Thomas Lee read and approved final version of manuscript.

\section{References}

[1] Kellum JA, Mehta RL, Angus DC, Palevsky P, Ronco C; ADQI Workgroup. The first international consensus conference on continuous renal replacement therapy. Kidney Int 2002;62:1855-1863.

[2] Mehta RL, Kellum JA, Shah SV, et al.; Acute Kidney Injury Network. Acute Kidney Injury Network: report of an initiative to improve outcomes in acute kidney injury. Crit Care 2007;11:R31.

[3] Mehta RL, Cerdá J, Burdmann EA, et al. International Society of Nephrology's 0by25 initiative for acute kidney injury (zero preventable deaths by 2025): a human rights case for nephrology. Lancet 2015;385:2616-2643.

[4] Case J, Khan S, Khalid R, Khan A. Epidemiology of acute kidney injury in the intensive care unit. Crit Care Res Pract 2013;2013:479730.

[5] Clermont G, Acker CG, Angus DC, Sirio CA, Pinsky MR, Johnson JP. Renal failure in the ICU: comparison of the impact of acute renal failure and end-stage renal disease on ICU outcomes. Kidney Int 2002;62:986-996.

[6] Hsu RK, Hsu CY. The role of acute kidney injury in chronic kidney disease. Semin Nephrol 2016;36:283-292.

[7] Faubel S, Chawla LS, Chertow GM, Goldstein SL, Jaber BL,
Liu KD; Acute Kidney Injury Advisory Group of the American Society of Nephrology. Ongoing clinical trials in AKI. Clin J Am Soc Nephrol 2012;7:861-873.

[8] Bonventre JV, Weinberg JM. Recent advances in the pathophysiology of ischemic acute renal failure. J Am Soc Nephrol 2003;14:2199-2210.

[9] Bonventre JV, Zuk A. Ischemic acute renal failure: an inflammatory disease? Kidney Int 2004;66:480-485.

[10] Devarajan P. Update on mechanisms of ischemic acute kidney injury. J Am Soc Nephrol 2006;17:1503-1520.

[11] Munshi R, Hsu C, Himmelfarb J. Advances in understanding ischemic acute kidney injury. BMC Med 2011;9:11.

[12] Havasi A, Borkan SC. Apoptosis and acute kidney injury. Kidney Int 2011;80:29-40.

[13] Wolfs TG, de Vries B, Walter SJ, et al. Apoptotic cell death is initiated during normothermic ischemia in human kidneys. Am J Transplant 2005;5:68-75.

[14] Han SJ, Jang HS, Noh MR, et al. Mitochondrial NADP+-dependent isocitrate dehydrogenase deficiency exacerbates mitochondrial and cell damage after kidney ischemiareperfusion injury. JAm Soc Nephrol 2017;28:1200-1215.

[15] Shen S, Zhou J, Meng S, et al. The protective effects of ischemic preconditioning on rats with renal ischemia-reperfusion injury and the effects on the expression of Bcl-2 and Bax. Exp Ther Med 2017;14:4077-4082.

[16] Wei Q, Dong G, Chen JK, Ramesh G, Dong Z. Bax and Bak have critical roles in ischemic acute kidney injury in global and proximal tubule-specific knockout mouse models. Kidney Int 2013;84:138-148.

[17] Vanden Berghe T, Linkermann A, Jouan-Lanhouet S, Walczak H, Vandenabeele P. Regulated necrosis: the expanding network of non-apoptotic cell death pathways. Nat Rev Mol Cell Biol 2014;15:135-147.

[18] Pefanis A, Ierino FL, Murphy JM, Cowan PJ. Regulated necrosis in kidney ischemia-reperfusion injury. Kidney Int 2019;96:291-301.

[19] von Mässenhausen A, Tonnus W, Himmerkus N, et al. Phenytoin inhibits necroptosis. Cell Death Dis 2018;9:359.

[20] Linkermann A, Bräsen JH, Darding M, et al. Two independent pathways of regulated necrosis mediate ischemia-reperfusion injury. Proc Natl Acad Sci U S A 2013;110:1202412029.

[21] Bonventre JV, Yang L. Cellular pathophysiology of ischemic acute kidney injury. J Clin Invest 2011;121:4210-4221.

[22] Molitoris BA, Sutton TA. Endothelial injury and dysfunction: role in the extension phase of acute renal failure. Kid- 
ney Int 2004;66:496-499.

[23] Sutton TA, Kelly KJ, Mang HE, Plotkin Z, Sandoval RM, Dagher PC. Minocycline reduces renal microvascular leakage in a rat model of ischemic renal injury. Am J Physiol Renal Physiol 2005;288:F91-F97.

[24] Kunugi S, Shimizu A, Kuwahara N, et al. Inhibition of matrix metalloproteinases reduces ischemia-reperfusion acute kidney injury. Lab Invest 2011;91:170-180.

[25] Kelly KJ, Williams WW Jr, Colvin RB, et al. Intercellular adhesion molecule-1-deficient mice are protected against ischemic renal injury. J Clin Invest 1996;97:1056-1063.

[26] Kelly KJ, Williams WW Jr, Colvin RB, Bonventre JV. Antibody to intercellular adhesion molecule 1 protects the kidney against ischemic injury. Proc Natl Acad Sci U S A 1994;91: 812-816.

[27] Singbartl K, Green SA, Ley K. Blocking P-selectin protects from ischemia/reperfusion-induced acute renal failure. FASEB J 2000;14:48-54.

[28] Kelly KJ, Molitoris BA. Acute renal failure in the new millennium: time to consider combination therapy. Semin Nephrol 2000;20:4-19.

[29] Sharfuddin AA, Molitoris BA. Pathophysiology of ischemic acute kidney injury. Nat Rev Nephrol 2011;7:189-200.

[30] Niemann-Masanek U, Mueller A, Yard BA, Waldherr R, van der Woude FJ. B7-1 (CD80) and B7-2 (CD 86) expression in human tubular epithelial cells in vivo and in vitro. Nephron 2002;92:542-556.

[31] Schofield ZV, Woodruff TM, Halai R, Wu MC, Cooper MA. Neutrophils--a key component of ischemia-reperfusion injury. Shock 2013;40:463-470.

[32] Kinsey GR, Li L, Okusa MD. Inflammation in acute kidney injury. Nephron Exp Nephrol 2008;109:e102-e107.

[33] Frangogiannis NG. Chemokines in ischemia and reperfusion. Thromb Haemost 2007;97:738-747.

[34] Heinzelmann M, Mercer-Jones MA, Passmore JC. Neutrophils and renal failure. Am J Kidney Dis 1999;34:384-399.

[35] Hellberg PO, Källskog TO. Neutrophil-mediated post-ischemic tubular leakage in the rat kidney. Kidney Int 1989;36: 555-561.

[36] Thornton MA, Winn R, Alpers CE, Zager RA. An evaluation of the neutrophil as a mediator of in vivo renal ischemicreperfusion injury. Am J Pathol 1989;135:509-515.

[37] Paller MS. Effect of neutrophil depletion on ischemic renal injury in the rat. J Lab Clin Med 1989;113:379-386.

[38] Nemoto T, Burne MJ, Daniels F, et al. Small molecule selectin ligand inhibition improves outcome in ischemic acute renal failure. Kidney Int 2001;60:2205-2214.

[39] Rabb H, Mendiola CC, Dietz J, et al. Role of CD1la and $\mathrm{CD} 11 \mathrm{~b}$ in ischemic acute renal failure in rats. Am J Physiol 1994;267:F1052-F1058.

[40] Li L, Huang L, Sung SS, et al. The chemokine receptors CCR2 and CX3CR1 mediate monocyte/macrophage trafficking in kidney ischemia-reperfusion injury. Kidney Int 2008;74:1526-1537.

[41] Oh DJ, Dursun B, He Z, et al. Fractalkine receptor (CX3CR1) inhibition is protective against ischemic acute renal failure in mice. Am J Physiol Renal Physiol 2008;294:F264-F271.

[42] Li L, Okusa MD. Macrophages, dendritic cells, and kidney ischemia-reperfusion injury. Semin Nephrol 2010;30:268277.

[43] Day YJ, Huang L, Ye H, Linden J, Okusa MD. Renal ischemia-reperfusion injury and adenosine $2 \mathrm{~A}$ receptor-mediated tissue protection: role of macrophages. Am J Physiol Renal Physiol 2005;288:F722-F731.

[44] Lee S, Huen S, Nishio H, et al. Distinct macrophage phenotypes contribute to kidney injury and repair. J Am Soc Nephrol 2011;22:317-326.

[45] Krüger T, Benke D, Eitner F, et al. Identification and functional characterization of dendritic cells in the healthy murine kidney and in experimental glomerulonephritis. J Am Soc Nephrol 2004;15:613-621.

[46] Dong X, Swaminathan S, Bachman LA, Croatt AJ, Nath KA, Griffin MD. Resident dendritic cells are the predominant TNF-secreting cell in early renal ischemia-reperfusion injury. Kidney Int 2007;71:619-628.

[47] Keller CW, Freigang S, Lünemann JD. Reciprocal crosstalk between dendritic cells and natural killer T cells: mechanisms and therapeutic potential. Front Immunol 2017;8: 570.

[48] Li L, Huang L, Sung SS, et al. NKT cell activation mediates neutrophil IFN-gamma production and renal ischemiareperfusion injury. J Immunol 2007;178:5899-5911.

[49] Takeda K, Akira S. Toll-like receptors in innate immunity. Int Immunol 2005;17:1-14.

[50] Leventhal JS, Schröppel B. Toll-like receptors in transplantation: sensing and reacting to injury. Kidney Int 2012;81: 826-832.

[51] Gluba A, Banach M, Hannam S, Mikhailidis DP, Sakowicz A, Rysz J. The role of Toll-like receptors in renal diseases. Nat Rev Nephrol 2010;6:224-235.

[52] Robson MG. Toll-like receptors and renal disease. Nephron Exp Nephrol 2009;113:e1-e7. 
Han and Lee. Mechanisms and therapeutic targets of ischemic AKI

[53] Arslan F, Keogh B, McGuirk P, Parker AE. TLR2 and TLR4 in ischemia reperfusion injury. Mediators Inflamm 2010;2010: 704202.

[54] Shigeoka AA, Holscher TD, King AJ, et al. TLR2 is constitutively expressed within the kidney and participates in ischemic renal injury through both MyD88-dependent and -independent pathways. J Immunol 2007;178:6252-6258.

[55] Wu H, Chen G, Wyburn KR, et al. TLR4 activation mediates kidney ischemia/reperfusion injury. J Clin Invest 2007;117: 2847-2859.

[56] Bamboat ZM, Balachandran VP, Ocuin LM, Obaid H, Plitas G, DeMatteo RP. Toll-like receptor 9 inhibition confers protection from liver ischemia-reperfusion injury. Hepatology 2010;51:621-632.

[57] Huang H, Evankovich J, Yan W, et al. Endogenous histones function as alarmins in sterile inflammatory liver injury through Toll-like receptor 9 in mice. Hepatology 2011;54: 999-1008.

[58] Xie L, Liu S, Cheng J, Wang L, Liu J, Gong J. Exogenous administration of mitochondrial DNA promotes ischemia reperfusion injury via TLR9-p38 MAPK pathway. Regul Toxicol Pharmacol 2017;89:148-154.

[59] Zhou Y, Pan J, Peng Q, Dong Z, Deng L, Wang Y. The TLR9 antagonist iCpG-ODN at different dosages inhibits cerebral ischemia/reperfusion injury in mice. CNS Neurol Disord Drug Targets 2017;16:624-633.

[60] Han SJ, Li H, Kim M, D'Agati V, Lee HT. Intestinal Toll-like receptor 9 deficiency leads to Paneth cell hyperplasia and exacerbates kidney, intestine, and liver injury after ischemia/reperfusion injury. Kidney Int 2019;95:859-879.

[61] Bakker PJ, Scantlebery AM, Butter LM, et al. TLR9 mediates remote liver injury following severe renal ischemia reperfusion. PLoS One 2015;10:e0137511.

[62] Li X, Yun Z, Tan Z, et al. The role of Toll-like receptor (TLR) 2 and 9 in renal ischemia and reperfusion injury. Urology 2013;81:1379.e15-1379.e20.

[63] Han SJ, Li H, Kim M, Shlomchik MJ, Lee HT. Kidney proximal tubular TLR9 exacerbates ischemic acute kidney injury. J Immunol 2018;201:1073-1085.

[64] Bauerle JD, Grenz A, Kim JH, Lee HT, Eltzschig HK. Adenosine generation and signaling during acute kidney injury. J Am Soc Nephrol 2011;22:14-20.

[65] Yap SC, Lee HT. Adenosine and protection from acute kidney injury. Curr Opin Nephrol Hypertens 2012;21:24-32.

[66] Eltzschig HK, Ibla JC, Furuta GT, et al. Coordinated adenine nucleotide phosphohydrolysis and nucleoside signaling in posthypoxic endothelium: role of ectonucleotidases and adenosine A2B receptors. J Exp Med 2003;198:783-796.

[67] Lee HT, Xu H, Nasr SH, Schnermann J, Emala CW. Al adenosine receptor knockout mice exhibit increased renal injury following ischemia and reperfusion. Am J Physiol Renal Physiol 2004;286:F298-F306.

[68] Joo JD, Kim M, Horst P, et al. Acute and delayed renal protection against renal ischemia and reperfusion injury with Al adenosine receptors. Am J Physiol Renal Physiol 2007; 293:F1847-F1857.

[69] Kim M, Chen SW, Park SW, et al. Kidney-specific reconstitution of the $\mathrm{Al}$ adenosine receptor in Al adenosine receptor knockout mice reduces renal ischemia-reperfusion injury. Kidney Int 2009;75:809-823.

[70] Day YJ, Huang L, McDuffie MJ, et al. Renal protection from ischemia mediated by A2A adenosine receptors on bone marrow-derived cells. J Clin Invest 2003;112:883-891.

[71] Day YJ, Huang L, Ye H, Li L, Linden J, Okusa MD. Renal ischemia-reperfusion injury and adenosine $2 \mathrm{~A}$ receptormediated tissue protection: the role of CD4+ T cells and IFN-gamma. J Immunol 2006;176:3108-3114.

[72] Grenz A, Osswald H, Eckle T, et al. The reno-vascular A2B adenosine receptor protects the kidney from ischemia. PLoS Med 2008;5:e137.

[73] Lee HT, Ota-Setlik A, Xu H, D'Agati VD, Jacobson MA, Emala CW. A3 adenosine receptor knockout mice are protected against ischemia- and myoglobinuria-induced renal failure. Am J Physiol Renal Physiol 2003;284:F267-F273.

[74] Lee HT, Emala CW. Protective effects of renal ischemic preconditioning and adenosine pretreatment: role of $\mathrm{A}(1)$ and A(3) receptors. Am J Physiol Renal Physiol 2000;278:F380F387.

[75] Lee HT, Kim M, Joo JD, Gallos G, Chen JF, Emala CW. A3 adenosine receptor activation decreases mortality and renal and hepatic injury in murine septic peritonitis. Am J Physiol Regul Integr Comp Physiol 2006;291:R959-R969.

[76] Ohana G, Cohen S, Rath-Wolfson L, Fishman P. A3 adenosine receptor agonist, $\mathrm{CF} 102$, protects against hepatic ischemia/reperfusion injury following partial hepatectomy. Mol Med Rep 2016;14:4335-4341.

[77] Maddock HL, Gardner NM, Khandoudi N, Bril A, Broadley KJ. Protection from myocardial stunning by ischaemia and hypoxia with the adenosine A3 receptor agonist, IBMECA. Eur J Pharmacol 2003;477:235-245.

[78] Koo TY, Lee JG, Yan JJ, et al. The P2X7 receptor antagonist, oxidized adenosine triphosphate, ameliorates renal 
ischemia-reperfusion injury by expansion of regulatory $\mathrm{T}$ cells. Kidney Int 2017;92:415-431.

[79] Yan Y, Bai J, Zhou X, et al. P2X7 receptor inhibition protects against ischemic acute kidney injury in mice. Am J Physiol Cell Physiol 2015;308:C463-C472.

[80] Rabadi M, Kim M, D'Agati V, Lee HT. Peptidyl arginine deiminase-4-deficient mice are protected against kidney and liver injury after renal ischemia and reperfusion. Am J Physiol Renal Physiol 2016;311:F437-F449.

[81] Ham A, Rabadi M, Kim M, et al. Peptidyl arginine deiminase-4 activation exacerbates kidney ischemia-reperfusion injury. Am J Physiol Renal Physiol 2014;307:F1052-F1062.

[82] Rabadi M, Kim M, Li H, et al. ATP induces PAD4 in renal proximal tubule cells via $\mathrm{P} 2 \mathrm{X} 7$ receptor activation to exacerbate ischemic AKI. Am J Physiol Renal Physiol 2018;314: F293-F305.

[83] Rabadi MM, Han SJ, Kim M, D'Agati V, Lee HT. Peptidyl arginine deiminase-4 exacerbates ischemic AKI by finding NEMO. Am J Physiol Renal Physiol 2019;316:F1180-F1190.

[84] Faubel S, Shah PB. Immediate consequences of acute kidney injury: the impact of traditional and nontraditional complications on mortality in acute kidney injury. $A d v$ Chronic Kidney Dis 2016;23:179-185.
[85] Cario E. Bacterial interactions with cells of the intestinal mucosa: toll-like receptors and NOD2. Gut 2005;54:11821193.

[86] Park SW, Kim M, Kim JY, et al. Paneth cell-mediated multiorgan dysfunction after acute kidney injury. J Immunol 2012;189:5421-5433.

[87] Park SW, Kim M, Brown KM, D'Agati VD, Lee HT. Paneth cell-derived interleukin-17A causes multiorgan dysfunction after hepatic ischemia and reperfusion injury. Hepatology 2011;53:1662-1675.

[88] Lee HT, Kim M, Kim JY, et al. Critical role of interleukin$17 \mathrm{~A}$ in murine intestinal ischemia-reperfusion injury. Am J Physiol Gastrointest Liver Physiol 2013;304:G12-G25.

[89] Jang HR, Gandolfo MT, Ko GJ, Satpute S, Racusen L, Rabb H. Early exposure to germs modifies kidney damage and inflammation after experimental ischemia-reperfusion injury. Am J Physiol Renal Physiol 2009;297:F1457-F1465.

[90] Andrade-Oliveira V, Amano MT, Correa-Costa M, et al. Gut bacteria products prevent AKI induced by ischemia-reperfusion. JAm Soc Nephrol 2015;26:1877-1888.

[91] Emal D, Rampanelli E, Stroo I, et al. Depletion of gut microbiota protects against renal ischemia-reperfusion injury. $J$ Am Soc Nephrol 2017;28:1450-1461. 